\section{LEARNINg Programming USING OBJECTS-FIRST APPROACH THROUGH FOLKTALES}

\author{
Ling Siew Woeia*, Imran Hazimin Othmana, Chuah Kee Man ${ }^{b}$ \\ aFaculty of Creative Multimedia, Multimedia University, Malaysia \\ bCentre for Language Studies, University Malaysia Sarawak, \\ Malaysia
}

Article history

Received

3 December 2013

Received in revised form

2 July 2014

Accepted

25 November 2014

*Corresponding author swling@mmu.edu.my

\section{Graphical abstract}

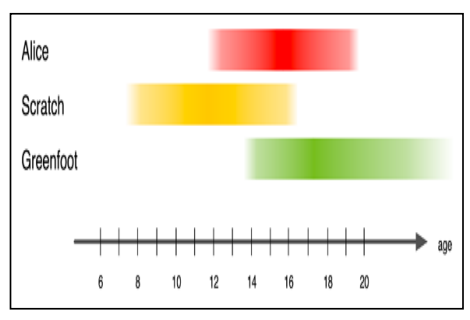

\begin{abstract}
Teaching programming to the amateur programmers and non-programmers with design and educational technology background are tough. Needless to say, it is pertinent for them to have some basic programming skills. We realized the needs to motivate the potential programmers therefore, proposed the integration of folktales in learning programming. This paper shares an approach of teaching programming using the folktales to create awareness also to simulate the amateur and non-programmers interested with folktales at the same time motivated to complete a creation of digital story using 3D programming software, Alice and Unity. Mixed-methods approach revealed participants' positive behavior towards learning programming although it was perceived difficult. The finding also indicates that they can understand the programming language and successfully explored the software to create a digital story.
\end{abstract}

Keywords: Digital story, non-programmers, Alice, unity, mixed-methods

(C) 2015Penerbit UTM Press. All rights reserved

\subsection{INTRODUCTION}

Various researches have been carried out to motivate non-programmers to learn programming languages [1], [2]. The importance of the programming language is seen with the skills and knowledge required to create Internet applications and also creative content for the evolving mass-consumption mobile devices such as Ipad, smartphones and other. Learning programming for non-programmers are especially challenging and we seek alternatives to lower the learning gap for programming language among the non-programmers.

The increasing prominence of Web 2.0 and ultimately Web 3.0 are sweeping the younger generation into a highly dynamic entertaining world whereby most of the physical appearance involves highly interactive and virtually designed objects, mostly in the 3-Dimensions. We instilled intrinsic motivation within the students by justifying the need to sustain their interest towards folktales. We have proposed the integration of folktales with programming for the non-programmers and amateur programmers using the object-first teaching approach. Objects-first "emphasizes the principles of object-oriented programming and design from the very beginning. It allows user to visualize the programming language with the notions of objects and inheritance [33]. It is the goal of this paper to shed light on how to sustain the interest of nonprogrammers and amateur programmers towards programming language by shifting their role as a folktales reader to become digital storyteller using 3D programming software.

\subsection{SUSTAINING FOLK STORIES}

\subsection{ICT-The Threats and Alternatives}

Folktale is a form of traditional story telling that exist long time ago when Information Computer and Technology (ICT) and technology were not present. It serves to entertain and to impart values to the younger generation [3] and often come in form of story narration carried out by parents due to illiteracy 